\title{
Marketing: uma ferramenta fundamental para o profissional da informação
}

\author{
Marketing: an essential tool for the \\ information professional
}

Cibele Roberta SUGAHARA ${ }^{1}$

Ligia Ferrari FUENTES²

Silas Marques de OLIVEIRA ${ }^{3}$

R E S U M O

O artigo analisa, em primeiro lugar, a importância da informação no mundo atual e a necessidade de tratá-la a partir da segmentação do mercado, apresentando o marketing como ferramenta capaz de desenvolver produtos e serviços e de comunicá-los a este mercado alterando e/ou influenciando o seu comportamento. A seguir apresenta os desafios que os profissionais da informação enfrentarão quando adotarem as técnicas mercadológicas, tendo como base discussões já apresentadas pelos pesquisadores Oliveira e Amaral. Na sua parte final propõe que os novos paradigmas do mundo atual e a utilização do marketing como ferramenta possam promover a aproximação e equilíbrio entre a técnica e a necessidade do usuário.

Palavras-chave: informação e marketing, profissional da informação, paradigmas.

\footnotetext{
1 Mestranda, Curso de Pós-Graduação em Biblioteconomia e Ciência da Informação, Pontifícia Universidade Católica de Campinas. E-mail: cibsrs@yahoo.com.br. Bolsista do CN Pq.

2 Mestranda, Curso de Pós-Graduação em Biblioteconomia e Ciência da Informação, Pontifícia Universidade Católica de Campinas. E-mail: ligia_ferrari@uol.com.br

3 Professor, Departamentō de Pós-Graduação de Biblioteconomia e Ciência da Informação, Pontifícia Universidade Católica de Campinas. Praça Imaculada, 105, Vila Santa O dila, 13045-901, Campinas, SP, Brasil. Correspondência para/ Correspondence to: S.M. Oliveira E-mail: silasmarques@hotmail.com

Recebido para publicação em 28/4/2003 e aceito em 11/8/2003.
} 


\section{A B S T R A C T}

Firstly the article analysis, the importance of information in the world today and the need to treat it from the market segmentation, introducing marketing as a tool able to develop products and services and to introduce them to this market changing and/or influencing its behavior. Secondly it presents the challenges that the information professional will face when they adopt the marketing tehniques, having as a base discussions already presented by the researchers Oliveira and Amaral. Finally it proposes the new paradigms of the present world and the marketing as a tool able to promote the approach and balance between the technique and the need of the user.

Key words: information and marketing, information professional, paradigms.

\section{N T R O D U Ç Ã O}

Com a explosão informacional que estamos presenciando desde as últimas décadas do século XX, as Unidades de Informação enfatizam ainda mais a necessidade de segmentar o mercado para tratar as informações de acordo com as demandas e desejos do seu público-alvo. Segundo Oliveira (1985, p.208):

A tendência hoje é a de que as alterações sociais estejam incluídas no contexto de marketing. Esse conceito está intrínseco no consenso geral de que marketing seja um processo pelo qual ocorrem trocas entre pessoas e grupos sociais.

Nesse contexto, abordamos o marketing como uma ferramenta fundamental na atuação do profissional da informação. E, para os fins desse artigo discutiremos, inicialmente, dois conceitos de marketing que para nós demonstram abrangência ao tratar da importância do marketing como ferramenta a ser utilizada pelos profissionais da informação.

No terceiro tópico apresentamos o que consideramos como desafios a serem enfrentados por estes profissionais, quando da adoção das técnicas mercadológicas, como alternativas que proporcionarão, de modo eficiente, a satis- fação das necessidades do público-alvo que se pretende atingir.

Finalizamos propondo uma reflexão sobre os novos paradigmas que afetam o profissional da informação, contextualizando o papel essencial deste profissional, na utilização dos novos canais de distribuição da informação de maneira ética e confiável. Conforme Amaral (1996, p.334):

Se não houver preocupação com o interesse da clientela/usuários, de nada adiantará o avanço tecnológico. Os produtos e serviços automatizados precisam respeitar e entender as necessidades e exigências de qualidade, confiabilidade, respeitando as peculiaridades específicas de cada comunidade.

$E$, concluindo, comentamos a necessidade da formação e preparação do profissional da informação, frente às tendências do século XXI, tendo como principal foco o usuário e não as tecnologias.

\section{Conceituando Marketing}

O conceito de marketing tem passado por uma evolução marcante durante a década de 1980, conforme Oliveira (1985, p.208): 
[...] ao contrário de ser definido como uma mera atividade preocupada apenas com a venda de produtos para se conseguir lucros financeiros, existe um consenso geral crescente de que marketing está relacionado ao desenvolvimento de produtos e serviços e à comunicação destes ao mercado potencial na expectativa de alterar e/ou influenciar o seu comportamento.

Então, conforme esse conceito, o profissional não deverá pensar em marketing, como no modelo clássico, em que bens e objetos são trocados por dinheiro, mas, nos benefícios psicológicos que as trocas de bens e serviços oferecem às pessoas que utilizam serviços de informação, como por exemplo, uma biblioteca.

Assim, marketing representará um esforço para provocar trocas e, através da comunicação e interação entre usuário e o profissional, os valores que estas trocas representam poderão satisfazer às necessidades dos usuários.

Kotler e Armstrong citados por Silva (1999/2000), conceituam marketing como sendo o resultado de trocas, de produtos ou valores, que representam a forma de como os indivíduos obtêm aquilo que desejam, como conseqüência de um processo social ou gerencial.

É interessante notar que, no momento da realização de trocas entre um sistema de informação e usuários, há um envolvimento social cujos valores efetivam as trocas.

O profissional da informação, ao adotar o marketing, precisará conhecer quem são os seus usuários e quais são suas necessidades, que mudanças ocorrerão como, aprimoramento das relações; estabelecimento de meios e ações para satisfazer suas necessidades, bem como, identificar seus usuários potenciais.

\section{Marketing como desafio para o profissional da informação}

Primeiramente, vamos definir o termo profissional da informação como sendo pessoas que exercem atividades por ofício, tendo como matéria-prima fundamental de trabalho a informação. Segundo Wurman (1992, p. 42) informação é "[...] a ação de informar, formação ou moldagem da mente ou do caráter, treinamento instrução, ensinamento, comunicação de conhecimento instrutivo".

Nesse sentido, o profissional da informação tem como responsabilidade produzir, tratar e disseminar a informação, objetivando satisfazer as necessidades e desejos de infor-mação do usuário no ambiente em que atua.

Definido o conceito de profissional da informação, o passo seguinte é explicar como este profissional utilizará o marketing como ferramenta.

$$
\begin{aligned}
& \text { Em relação à literatura de } \\
& \text { marketing para unidades de } \\
& \text { informação, Silva (1999/2000), } \\
& \text { observa o início da abordagem } \\
& \text { mercadológica para os serviços } \\
& \text { bibliotecários, verificando a } \\
& \text { necessidade da segmentação } \\
& \text { do mercado com a finalidade de } \\
& \text { satisfazer demandas, desejos e } \\
& \text { necessidades dos usuários. }
\end{aligned}
$$

Essas demandas surgem em busca de melhorias em relação ao atendimento do usuário, qualidade dos serviços e diversidade de bases de dados. Nesse contexto, o profissional da informação precisa focar o ambiente em que opera, enfatizando as relações de trocas com o mercado-alvo e, desta forma, a informação sobre o usuário é um recurso que bem formulado garante a sobrevivência da organização. Segundo Ottoni (1996, p.171)

O marketing em unidades de informação pode ser entendido como uma filosofia de gestão administrativa na qual todos os 
esforços convergem em promover, com a máxima eficiência possível, a satisfação de quem precisa e de quem utiliza produtos e serviços de informação.

Assim, o profissional da informação utilizando o marketing pode, através do acúmulo de informações coletadas sobre o comportamento e necessidades dos usuários traçar seus perfis no intuito de conhecer melhor seus desejos e necessidades.

Quando os administradores de Unidades de Informação aplicam marketing nas suas "transações", estão preocupados não apenas em satisfazer a demanda já existente, mas também em buscar inovação mercadológica. Amaral (1996, p.332), afirma que

[...] a adoção do marketing em unidades de informação é vista como uma forma de valorizar o profissional da informação, meIhorando sua imagem mediante o uso aprimorado de técnicas para fazer trocas adequadas, quebrando as barreiras na comunicação entre as unidades de informação e seus usuários para melhor satisfazer às necessidades informacionais desses usuários.

O profissional que trabalha em unidades de informação, seja ela denominada biblioteca, centro/serviço, departamento ou setor de documentação, informação ou qualquer outra designação, precisa entender que, segundo Amaral (1996, p.330), "[...] informação não pode ser considerada somente como um bem econômico, uma vez que a informação não se limita a um simples produto ou matéria-prima de uso doméstico." A informação é um fator essencial que permite o salto para a verdadeira transformação da sociedade, pois é de fundamental importância para a geração de conhecimento, já que na sociedade pós-industrial a informação passou a ser o insumo básico para o seu desenvolvimento.

Ao vislumbrarmos informação sob esse ponto de vista, a atuação dos profissionais nas unidades de informação deverá ter como uma das premissas o interesse em satisfazer as necessidades de informação dos usuários e a preocupação com o seu constante aprimoramento, mantendo-se, assim, preparados para enfrentar esta realidade.

Novas tecnologias, certamente, irão compor o cenário de concorrências junto às organizações informacionais. No entanto, essas organizações deverão ter sempre como principal foco o usuário que irá atender. Assim, sob esse novo enfoque há que se buscar equilíbrio entre as necessidades dos usuários, as expectativas do mercado e as formas organizacionais da unidade de informação, considerando-a sob a ótica mercadológica.

Nesse aspecto, para Amaral (1996, p.331-332):

[...] o marketing pode ser visto como um processo gerencial, valorizando as trocas voluntárias de valores para garantir a sobrevivência das organizações, sendo entendido como uma combinação de técnicas, cuja aplicação visa ao perfeito processo de troca, beneficiando todos os elementos que nela interagem.

O profissional da informação, sendo conhecedor das inovações mercadológicas e das estratégias de planejamento utilizadas pelo marketing, certamente estará contribuindo para o desenvolvimento social, econômico, político e cultural da sociedade.

O profissional da informação que adotar as técnicas mercadológicas estará visualizando a unidade de informação como um "negócio", cuja missão é satisfazer as necessidades do usuário, procurando aprimorar a prestação de serviços. 
No entanto, adotar essas técnicas significa mudança no planejamento das unidades e, para isso, o profissional deverá receber, na sua formação, treinamento e preparo para atuar diretamente na sociedade. Ele deverá assumir compromisso em relação às responsabilidades sociais que terá frente às inovações tecnológicas e competitivas que o desafiarão. A sua postura deverá ser a de manter-se constantemente atualizado, participando de cursos de capacitação e mantendo-se estreitamente ligado às inovações tecnológicas.

É fundamental que tenham conhecimento, ao adotar o marketing, que, a informação e o usuário modificam a política, a educação, a cultura, a economia de uma sociedade, daí a sua responsabilidade junto à comunidade em que atua.

De um modo geral, o profissional da informação, é treinado e competente na organização e estruturação de suas unidades. O novo desafio é facilitar o acesso e disseminar a informação de fontes confiáveis para um número cada vez maior de usuários. E, neste ponto, o marketing irá aproximá-los. Essa aproximação não resolverá todos os problemas sociais, mas contribuirá para o desenvolvimento de uma sociedade mais justa e democrática. Assim, cônscio das suas responsabilidades, utilizará as estratégias de marketing para divulgar os seus produtos e serviços, manter atualizado seu arquivo, assegurar apoios financeiros, estando permanentemente conectado ao atendimento das necessidades do seu público-alvo.

\section{O Profissional da informação e os novos paradigmas}

Com o avanço acelerado da tecnologia, surgem novos paradigmas alterando e criando novos canais de distribuição da informação, como o computador, a teleconferência e a Internet. Nesse cenário pode-se assegurar que o profissional da informação continua sendo o agente principal dessa nova sociedade responsável pela disponibilização de informações confiáveis e adequadas e, neste contexto, as novas tecnologias são ferramentas que facilitam a busca, recuperação e disseminação do insumo essencial da nova era, a informação. Na visão de Amaral (1999/2000, p.179):

O novo paradigma para o século XXI valoriza a ética, a qualidade e a convivencialidade, que sucede a competição. É preciso entender e passar para o lado do consumidor, adotando uma atitude de simpatia e empatia na oferta da informação.

Pode-se dizer que, antes de aplicar o marketing em unidades de informação, as pessoas precisam saber em qual ambiente a organização está inserida, através do mapeamento da cultura, valores e crenças, como relata Amaral (1999/2000, p.181) "Isto contribuirá para aprimorar sua capacidade de comunicação e suas relações com seus públicos [...]".

As duas décadas passadas foram de suma importância no que concerne às mudanças intelectuais e tecnológicas que a ciência vem experimentando. Algo mudou e mudou para sempre. Para Santos (1989, p.45):

[...] é necessário, encontrar um novo equilíbrio entre adaptação e criatividade, por uma compreensão da ciência que obrigue o homem a refletir sobre os custos e os benefícios entre o que pode fazer e o que lhe pode ser feito [...] dar à técnica o que é da técnica e à liberdade o que é da liberdade.

Mudanças estão ocorrendo em todas as áreas do conhecimento acarretando grandes transformações na sociedade global. De maneira geral, as pessoas são refratárias às mudanças talvez por medo, talvez por tradição, talvez por temerem assumir novas responsabilidades. Mas a ruptura já ocorreu e, portanto, mais do que 
nunca é preciso adequação e capacitação para esses novos tempos. Nesse novo contexto, o conceito de informação evoluiu na medida em que houve a evolução dessa nova sociedade.

Atuando em sua unidade de informação seja ela uma biblioteca pequena ou um centro de inteligência competitiva de uma grande empresa, o desempenho do profissional da informação deverá ser voltado ao desejo do usuário. O profissional da informação deve saber que sua atuação representa um importante papel na nossa sociedade, mas, infelizmente, conforme Amaral (1999/2000, p.178) há escasso conhecimento sobre marketing entre os profissionais da informação. A autora também critica o fato de termos escassa literatura a respeito. Faz-se necessário o treinamento desses profissionais, para a divulgação e acessibilidade de material em língua portuguesa e, a aproximação desses profissionais com os profissionais especialistas em marketing que irão disponibilizar treinamentos das técnicas utilizadas nesta área.

O novo profissional da informação deverá ser capaz de encontrar o equilíbrio entre a técnica e a necessidade do usuário. Utilizar-se de tecnologias de comunicação no marketing é um caminho importante a ser trilhado por ele que, conforme tendência do século XXI deverá ser criativo e inovador.

\section{RE FER Ê N CIAS}

AMARAL, S.A. Marketing e desafio profissional em Unidades de Informação. Ciência da Informação, Brasília, v.25, n.3, p.330-336, 1996.

AMARAL, S.A. O profissional da informação e as técnicas de marketing. Revista de Biblioteconomia de Brasília, Brasília, v.23/24, n.2, 1999/2000, p.173-188, Edição Especial.

OLIVEIRA, S.M. Marketing e sua aplicação em bibliotecas: uma abordagem preliminar. Ciência da Informação, Brasília, v.14, n.2, p.207-227, 1985.

OTTONI, H.M. Bases de marketing para unidades de informação. Ciência da Informação, Brasília, v.25, n.2, p.171-176, 1996.

\section{CONSIDERAÇÕ ES FINA IS}

Nesse artigo, fizemos uma reflexão sobre o papel de suma importância que o profissional da informação exerce nestes tempos de alta tecnologia informacional em que vivemos.

Abordamos, também, a necessidade desse profissional estar em conexão com seu público-alvo, pois a informação só cumprirá seu papel se, primeiramente, houver percepção, por parte dos usuários, em obter informação que possa contribuir para a satisfação dos seus interesses, agregando valores e acarretando alterações no seu comportamento.

Se houver a preocupação de transmitir, no momento da formação do profissional da informação, a utilização do marketing como ferramenta que contribui para a aproximação dos profissionais, do seu público-alvo, certamente este poderá ser um caminho para alterações consideráveis no comportamento da sociedade, pois estará propiciando um atendimento especializado focando as necessidades dos usuários.

Assim, o marketing em unidades de informação, surge como uma alternativa para facilitar a transferência de informações dirigidas ao atendimento de um determinado público.

SANTOS, B.S. Da dogmatização à desdogmatização da Ciência Moderna. In: SANTOS, B.S. Introdução à Ciência Pós-Moderna. Rio de Janeiro: Graal, 1989. Cap. 2-3, p. 17-45.

SILVA, A.F.G. Marketing em unidades de informação: revisão crítica. Revista de Biblioteconomia de Brasília, Brasília, v.23/24, n.1, 1999/2000, p. 5-23 Edição especial.

WURMAN, R.S. A Explosão da Não-Informação. In: WURMAN, R.S. Ansiedade de Informação. São Paulo: Cultura, 1992. Cap.1, p.35-55. 